\title{
Semiotics with Style and Situation: Multi-modal Comparative Analysis of Cover pages of Native and Non-native English Novels
}

\author{
Manvender Kaur Sarjit Singh, ${ }^{1}$ Muhammad Imran Shah, ${ }^{2 *}$ \\ Eram Jamil, ${ }^{3}$ Rabia Feroz ${ }^{4}$ \\ ${ }^{1}$ School of Languages, Civilization, and Philosophy, College of Arts and Sciences, Pakistan; \\ ${ }^{2}$ Government College University Faisalabad, Pakistan, University Utara Malaysia; ${ }^{3}$ University of \\ Sargodha Sub Campus Bhakkar, Pakistan; ${ }^{3}$ University Utara Malaysia; ${ }^{4}$ Government College \\ University Faisalabad, Pakistan
}

*) Corresponding Author

Email m.imran.shah@gcuf.edu.pk

DOI: 10.18326/rgt.v14i2.263-282

Submission Track:

Received: 28-08-2021

Final Revision: 01-12-2021

Available Online: 05-12-2021

Copyright @ 2021 Author(s)

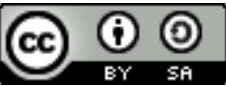

This work is licensed under a Creative Commons Attribution-ShareAlike 4.0 International License.

\begin{abstract}
The communicative function of text can be obtained through the multimodal analysis of the text, which contains the interaction and integration of two or more semiotic resources, graphics and text. This study investigates the structure of the titles and graphics of the cover pages along with the situation of the content of title pages of English novels of modern age composed by native and non-native authors. Four title pages including two modern native and two non-native English novels are randomly selected from the Google search engine. Followed is multimodal analysis, including Jeffries' (2016) model to analyse the structure of the text of the title (cover) pages, Davy's (2013) model to analyze the graphical features of the cover pages, and Bernstein's (2003) model to investigate the situational features presented in the cover pages of the novels. The textual, graphical and situational features present in title pages of English novels by the native authors were compared with the nonnative authors by feature identification based on Multimodal approach. It has been found that the native authors have agreed with the publishers who provide information about the content of the novel in the setting of the cover page as they followed the models while composing the cover pages of the novels, whereas the non-native authors and publishers have not given enough information in the setting of the cover pages. It seems that they do
\end{abstract}


not follow the mentioned models thoroughly. It causes lack of readership as the readers cannot extract maximum information from the cover page. The study has opened new dimensions for the new researchers and it is also beneficial for the authors and publisher in the selection of the title pages.

Keywords: semiotics; graphics; situation; text; title-page

\section{INTRODUCTION}

There is widespread consensus that the word paper refers not only to written text but also to graphic images, photographs, and artefacts. Twyman's (1979) concept of graphic language as "two-dimensional, deliberate, visible communication" leads to a view of graphic language documents as "any conventional alphanumeric text" as well as "any combination of text, graphics, and/or pictures, and illustration." To reconcile the conventional text-based document with the picture as document in the digital world, Twyman's concept of graphic language documents can be extended to all displays of signs and symbols. Similarly, colors mirror some ideological concepts that can be visualized, reflecting meanings through images; "color projection was emphasized in ancient literature as an important aspect of life" (Niazi et al, 2015, p.1). Form these elements such as glyph, icons and images like drawings and photographs, the author can add more of his ideas while communicating his message through text.

Advertising is the technique used to bring products, "services or opinions to public notice for the purpose of convincing the public to respond in a particular way toward what is advertised" (Shariq, 2020, p. 565). That product can be a title page of a book or a novel. Advertisements for the title pages of novels are most effective when the graphics stand out while maintaining the relevance and clarity of the message. Advertisements are the first and foremost step to make a product attractive and effective (Vasiloaia, 2009). There is the frequent use of figures of speech and other typical stylistic devices such as puns, metaphors, neologisms, alliteration, assonance, or rhyme in the language of advertising. These devices are highly creative in the language of advertising and they contribute to the secondary function of advertising to entertain the recipients. Many researchers (Vasiloaia, 2009; Culpeper et al, 2009; Fomukong, 2016) have analysed the language of advertisements in various ways using different methods and data. Moretti (2009) posits that titles are the best way to 
go beyond the 1 percent of novels that make up the canon to catch the glimpse of the literary field as whole. Bouza (2017) analyzes the title pages of eighteenth-century grammar books and associated the pragmatic function of the title page with the increasing social value of the English language. Very little work before this study attempted a multimodal approach to analyze the title pages of the English novels at graphic, textual and situational level.

The purpose of this study, particularly, is to analyze of title pages, which contain the interaction and integration of two or more semiotic resources, graphics and text, in order to obtain the communicative functions of the text. Not only does this study investigate the style of the titles and graphics of the title pages with the situation presented in the content but it also compares these features on the title pages of native and non-native selected English novels.

The present study has tried to explore the structural variations in the titles of native and non-native English novels and to highlight different graphical variation in the title pages of native and non-native English novels.

\section{LITERATURE REVIEW}

The underlying theory for this research investigation is very much influenced by the theoretical structure of Jeffries' Textual Conceptual Functions (TCFs) suggested in the field of linguistics.

"Multimodal research explores communication in all of its types, but it is especially interested in texts that involve the interaction and incorporation of two or more semiotic tools or 'modes' of communication to achieve the texts communicative functions" ( $O$ 'Halloran 2010, p.2). The process of understanding and making sense of qualitative data in projects that combine verbal and nonverbal types of knowledge is known as multimodal analysis ( $O^{\prime}$ Halloran 2010). It is a wide field of methodological research that involves the study of human movements and other nonverbal communication, as well as images, video, sound, and 3-D materials. Social semiotics, interactional sociology, and sensory anthropology are three significant theoretical influences on the growth of multimodal research (Dicks, 2019). Each has created distinct ontologies of the object of analysis, as well as unique conceptions of key analytic phenomena, despite the fact that their bodies of work are far from clearly defined such as 
"reflexivity," "context," and "meaning," as well as various research vocabularies. There are also variations in how "information" is described, transcribed, and analyzed, as well as how cameras are used and how the researcher "sees" the field of study. The communicative power of utterances is derived in part from the model resources they use, where speech-for example-provides attributes, or "affordances," of meaning that writing or images do not. Given that language encompasses a variety of "modes" of communication, including human modes including gesture, gaze, speech, prosody, and bodily motions, as well as nonhuman material/virtual modes, (e.g., the materiality of objects, the visuality of images, the orality of soundscapes), the ways in which modes provide distinct symbolic repertoires for a wide spectrum of communication in both human and nonhuman material forms is worth exploring (Dicks, 2019, P.17).

Jeffries (2016) uses Textual Conceptual Functions as tools: prioritization, implying and assumption, listing, naming and description (p.109). When we choose what details to highlight in a sentence, we are prioritizing. It draws attention to a specific piece of information by concentrating on the sentence's information structure in three respects. These include putting new and relevant information at the end of the sentence, using the passive sentence's final clause elements, and putting less important information in the subordinate clause. This research looks at prioritizing from the perspective of graphology, or preferring to highlight those details with capitals and bolds. According to Crystal (2003), language of title pages has a deviant graphology.

Stylistic considerations only come into play when we start selecting features from the language as a whole and relating them to situational variables using different quantification techniques, with the method of selection being meaningless for most other linguistic purposes (Davy, 2013).

The setting in which the text comes to life is referred to as the situation. During the act of speaking or writing, the context of the situation can be entirely detached from what is going on around you. If the situation is to be included in a general sociolinguistic theory, it will need to be interpreted in even more abstract terms: and to think of it as a situation type, rather than a situation, in the sense of what Bernstein calls a social context. This is a semiotic structure in 
nature. The community is made up of a constellation of meanings originating from the semiotic system.

A slogan is a brief, memorable phrase that encapsulates the importance of a product. It reflects the brand's personality, creates a sense of liability in the brand name, and is used to send a message about the product's service. Fomukong and his colleagues (2017) looked at the structural patterns of clauses and groups found in slogans posted by various businesses in Bamenda, Cameroon's north West Region, on billboards, bar walls, and doorposts. The analysis is based on Halliday's Rank Scale systematic approach. The results show that slogans use a variety of structures, including declarative, imperative, nonfinite verbal clause, parallel structure, nominal group, prepositional group, and adverb group, all of which work to persuade customers to buy their products in the various ways they operate (Fomukong et all., 2017).

\section{RESEARCH METHOD}

The philosophical stance of the present study is very much influenced by the post-positivistic school as the observations based on the hypothesis conceptualized with the help of theories and models propounded by great theorists, discussed in literature review segment of the study.

The data selected for this research study comprises of the title pages of modern English novels composed by native as well as non-native authors. As it is a descriptive study based on Multimodal approach, the cover pages of selected novels have been focused to find out stylistics as well as semiotics features. Data was collected based on English novels of modern era by native and non-native authors. The novels were particularly selected from year 1984 to 2021. First, the title pages of the modern English novels by native author were searched on google search engine. To avoid bias, we just mentioned modern novels in Google search key. It showed the list of title pages of English novels. The first two title pages of English novels by native authors were selected. Then, the same process was done for the collection of title pages of English novels by non-native authors as mentioned in the below list.

The researcher has followed Jeffries (2016), Davy (2013) and Bernstein's (2003) models as a tool of research to analyze the stylistics as well as graph- 
logical features of the text and graphics of the title pages accordingly. The researcher used a qualitative descriptive approach to analyze data through qualitative and content analysis approach. First, the researcher analyzed the data through Lessely Jeffries' (2016) model of textual conceptual functions to answer the first research question that is "what are the structural variations in the titles of native and non-native English novels?" Situational and contextual features of the collected data are analyzed through Bernstein (2003). Then the second research question-"what are the different graphical variations in the title pages?" - was answered with the help of Davy's (2013) model of stylistical analysis to analyse the Graphics and pictures of the cover pages of English novels by native and non-native composers or publishers. Now, in the preceding section of this chapter the individual title pages are being analyzed while following the TCF's, semiotic, and stylistical theory propounded by Jeffries, Bernstein and Davy respectively.

\section{RESULTS AND DISCUSSION}

Analysis of the title page of the novel "The Catcher in the Rye" by "J.D. Sainger" retrieved from "goodreads.com"

According to Jeffries (2016), the text on the title page appearing includes the title as well as name of the author. Author composed the phrase of the title of this novel in a simple structure. The title comprises of the noun phrase and the prepositional phrase.

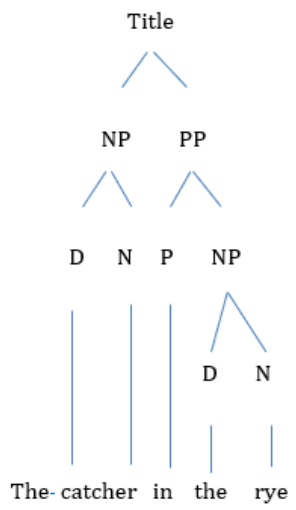


Figure 1

The Catcher in the Rye

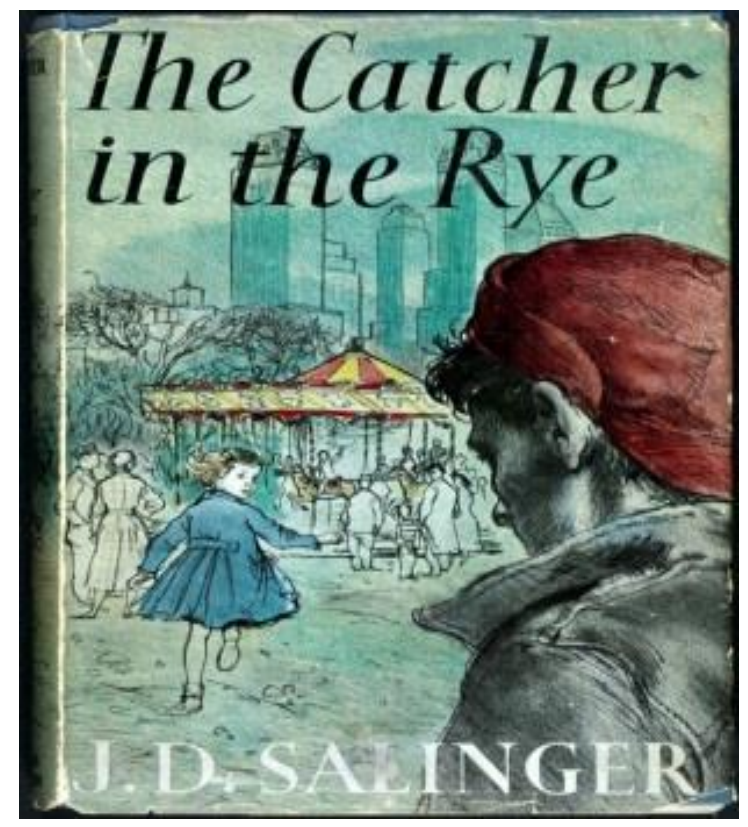

Rye is a proper noun whereas catcher is a common noun but the definite article with catcher making it more significant with reference to the Rye and it raises curiosity among the readers who wish to explore the significance of the catcher in Rye. Author has used black color in the title phrase "the catcher in the Rye," which creates suspicion that something is mysterious. According to Adams (2008), the colour black conjures up images of evil, death, power, mystery, and fear. Black has almost negative implications in the literature. He has bolded the first letter of the statement to emphasize its importance on the title page. The writer has used white hue for his own name, which contrasts with his character's dark tint. White is a colour of calmness that brings consolation by providing brightness to the darkness of black. All the letters are capitalized and bold, which made the text a prominent one on the title page.

According to Davy (2013), graphics used in this title page is a picture with different colors. There are a man, a young girl, some buildings, a tree and other people in the picture. The picture shows that the facial expression of the man 
reveals that he is in anger and staring at the young girl. The girl is running away from the man but still looking at him backwards in an innocent way as the expression of the little girl revealing that there is some obnoxious relationship between the girl and man. The man is wearing a black coat or jacket; evil, death, power, mystery, and terror are all represented by this sign. The colour black has a negative meaning. It invites scrutiny since it readily reveals impurities (Adams, 2018). The color of the man's face and clothes are the same but the hair is dark red. It represents that the man is overwhelmed with dangerous designs like devastation, forewarning, and harassment, as the red colour symbolizes all these ideas. The man's features display rage and blood in his thoughts, indicating that his views are really heinous. The title page has a bright blue theme. Blue is the main colour in every colour space model. It is the hue of the sea and the sky, and it is generally associated with peace, stability, inspiration, wisdom, and good health. It can be a soothing colour (Cerrato, 2012). The girl is wearing a light blue mini frock. Her face color is white, which signifies goodness, innocence, and her purity. It is the color of perfection. White is a colour associated with safety, purity, and cleanliness. Unlike black (the colour of the man in the picture), white is usually associated with positivity (Cerrato, 2012). She has short black hair. The background color of the title page is sky blue, which is the same as the color of the buildings shown in the pictures. All the other human beings in the picture are of white color and wearing white clothes, which is the color of peace. The tree in the picture is off black color. All the colors used in the picture are light except the hair color of the man.

The situation according to Bernstein (2003) shown in the picture depicts that Rye is a city in New York, which is full of life. All the people are busy in their own. In this situation, the catcher is shown as a sign of threat. He has anger on his face and blood in his mind. The girl is innocent and running away from the man as it feels like the person wants to catch the girl. The size of the male's picture in the title page is bigger than any one, which represents that author focused more on the Catcher. In a bird's eye view, the title page gives the maximum information about the content present in the text of this piece of literature. 


\section{Analysis of the title page of the novel "The return of the native" by "Thomas Hardy" retrieved from "goodreads.com"}

Figure 2

The Return of the Native

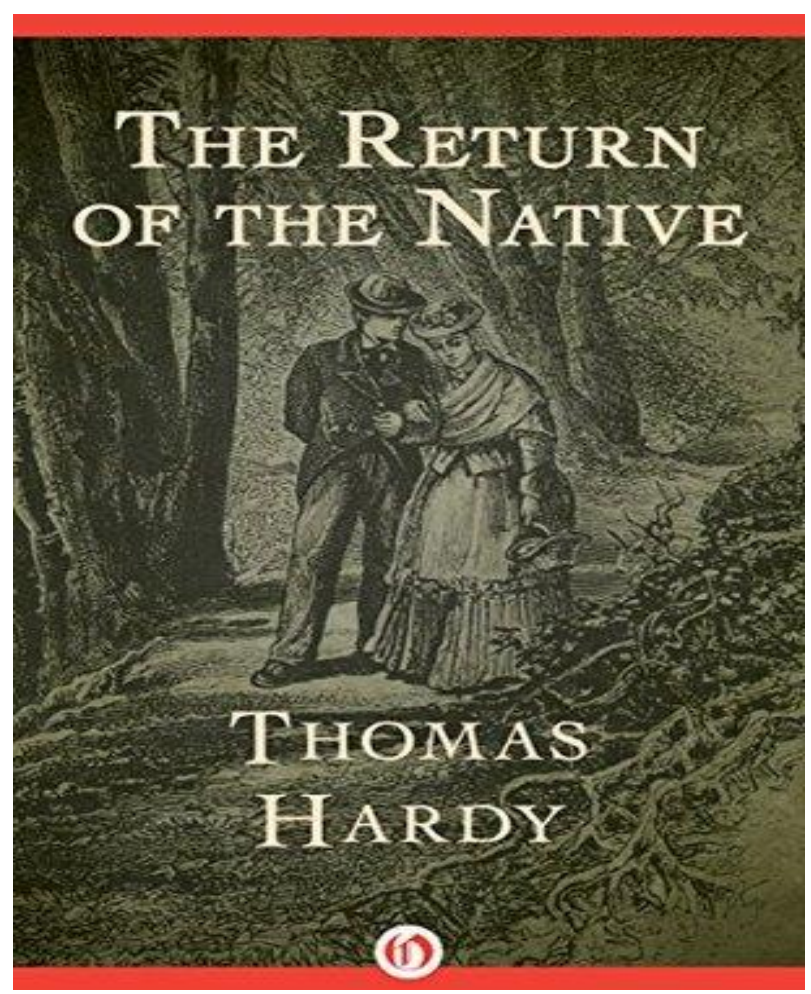

The text on the title page appearing includes the title as well as the name of the author. The author composed the phrase of the title of this novel in a simple phrase (Jeffries, 2016). The title comprises of the noun phrase and the prepositional phrase.

'Native' as well as 'return' are common nouns here but the definite article 'the' with both of them making them proper ones with reference to the text. 'Return' is performing the function of abstract noun here not the verb because it is giving the meaning of coming back here in the title. The author intentionally 
put the 'the return' at thematic position in the title. A noun is a grammatical form that refers to a person, creature, place, thing, or idea. Subjects are nouns. Every sentence has a subject, which is a word or phrase that tells us what the statement is about. Prepositions link nouns, pronouns, and phrases to other words within a phrase. They show how their item is related to another word or part of a phrase in terms of time, space, or logic. The preposition "of" is a basic preposition that connects the noun and the prepositional phrase. This noun phrase is memorable and piques the readers' interest. The native's return sparked some heated debate. The title of the novel and the author's name were written in white, which represents perfection, innocence, and purity (Cerrato, 2012). The letters in the novel's title and author's name are all capital, bold, and the same size.

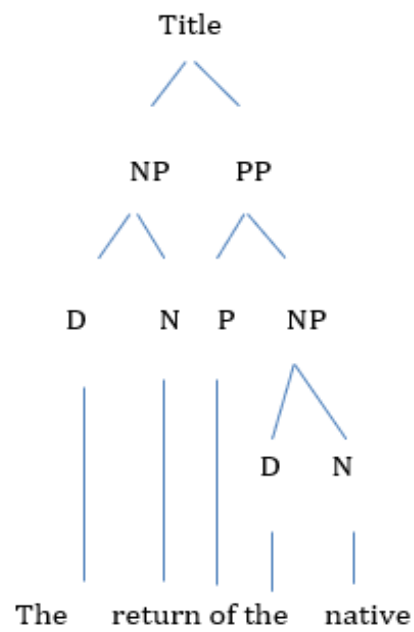

Graphics used in the title pages according to Davy (2013) is the picture of a forest where the man and woman standing in an amours design. The publisher used black color in the background of the title page to show the depth of gloom, seriousness. He presented their love in intense circumstances and severe conditions. Black color generally symbolizes the somber and severity of the situation. Black is connected with evil, death, power, mystery, and terror (Adams, 2008). Black has both positive and negative implications. The title 
page's background colour is a blend of black and white. It presents the mixed idea of love, death, separation and purity in the title page.

The setting of the above title page presents that the return of natives discusses the natural intimacy with the opposite sex and associated it with nature; but the color used by the author is somber and depicts the severity of the situation. Picture used in the title depicts that Hardy is a nature lover. Obviously, he has given certain expressions of natural scenes in the content and he also approves the same title pages relevant to his title page (Bernstein, 2003).

\section{Analysis of the title page of the novel "Salt and Saffron " by "Kamila Shamsie" retrieved from "goodreads.com"}

\section{Figure 3}

Salt and Saffron

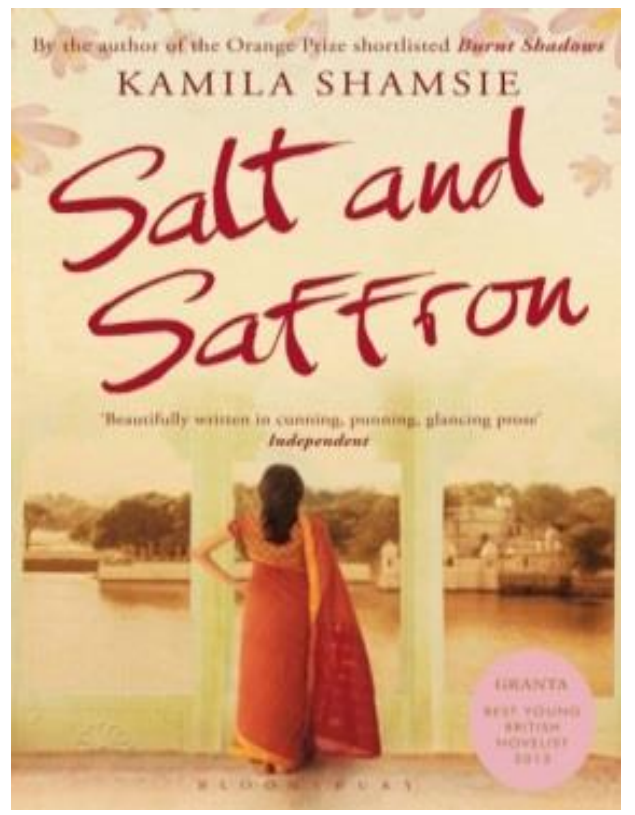

The phrase of the title of this novel in a simple structure. The title comprises of two noun phrases connected with a conjunction. 


\section{Title}

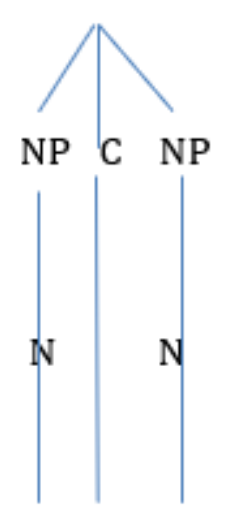

\section{Salt and -Saffron}

'Salt' and 'Saffron' are common nouns. A generic term for a person, place, or item in a class or group is a common noun. A common noun is not capitalized unless it is the first word of a sentence or appears in a title, as the author did in the novel's title. The conjunction 'and' connects the two common nouns. The conjunction 'and' is a coordinating conjunction, which joins items of equal syntactic importance and grammatical rank. They have the ability to connect two separate phrases, classes, and sentences. In the given title of Kamila Shamsie's novel, the coordinating conjunction serves to link two noun phrases in the title that have the same grammatical rank. The title of the novel, as well as the author's name, is written in red. In the title of the literary composition, he has employed the literary device of 'alliteration.' Two consonant sounds, the ' $S$ ' sound, are repeated in alliteration, which is a literary device used to beautify the sonic effects of the text. The colour red is associated with vitality. It conjures up images of movement and excitement. It is utilized to get people's attention. It is frequently where the eye is drawn initially as a signified in the titled phrase (Meghamala et al, 2016). The author capitalized the first letter of the nouns according to the definition of common noun. She put the title in bold and made the font size larger than the font size of her own name. She has capitalized all the letters of her own name but not bold. 
Graphics used in the title pages according to Davy (2013) is the picture of a historical place where a woman wearing Indian dress is standing near an artificial lake. It signifies that she is talking about a woman in her novel. That girl must have some connection with the historical places as the picture gave the information. The girl is contemplating and bowing her head before the building. The lake used in the picture of the title page represents depth, serenity, mystery and silence with calmness. The woman in the picture is wearing the dress of red and orange color. The colour orange is associated with ambition. Orange is energizing, and people's reactions to it are a mix of the physical and the emotional. It concentrates our thoughts on physical comfort, such as food, warmth, shelter, and pleasure (Meghamala et al, 2016, p.117). Red is a colour that conjures up images of love and passion. It also conveys vitality and strength. Some people are energized by the colour red, whether they are wearing it or witnessing it. This colour creates an enthralling atmosphere (Niazi, Ahmad \& Aftab, 2015). The red tint indicates that the author may be discussing the woman in the picture's love life.

Setting the title page according to Bernstein (2003), shown is information that the author wrote the story of a girl who is living somewhere away from her family. She has her love life as the red color used in the title page indicates. The author has used all the graphical features very carefully that it is the wit of writer that he is going to associate his content with the title page in order to attract the attention of the reader in order to grab the attention of the reader. A mature readers ultimately deduces a lot of knowledge while watching or observing the mare title page of the piece of literature.

\section{Analysis of the title page of the novel "the women's Courtyard " by "Khadija Mastaur" retrieved from "goodreads.com"}

The text on the title page appearing includes the title as well as name of the author. The author composed the phrase of the title of this novel in a simple structure (Jeffries, 2016). The cover comprises of the noun phrase.

The author has comprised the title of a noun phrase. The noun phrase consists of a plural noun 'women' and common noun 'courtyard.' The determiner 'the' is used before a word to indicates that the sentence will be qualified or defined later. 


\section{Figure 4}

\section{The Women's Courtyard}

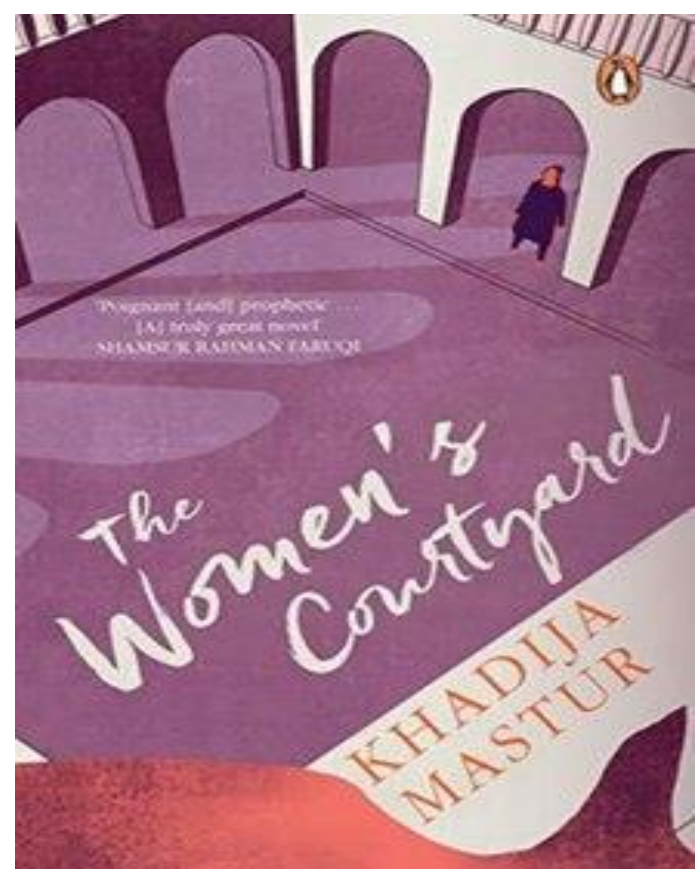

The author has used the apostrophe with the plural noun to show that the courtyard is owned by women. He used the plural term 'women' to refer to the entire group of women addressed in his text. He used white ink to create the novel's title and orange ink to write his own name. Passion, intrigue, creativity, determination, attraction, and stimulation are all represented by the colour orange, which is a bright, vibrant, and warm colour. Orange is often used to draw attention e.g. in traffic signs and advertising. It is the hue of the risk-taker, the extrovert, and the unconstrained, and it's a mix of energy and fun. It represents adventure, optimism, self-confidence, and friendliness in colour psychology. The colour white is associated with perfection, innocence, and purity. The author utilized the same colour scheme to approve the title phrase as well as his own name (Cerrato, 2012). He has used different style to write the text on the title page. All the letters in the title of the novel are bold and large in 
size. He wrote his own name in capital letters that has made the text prominent one on the title page.

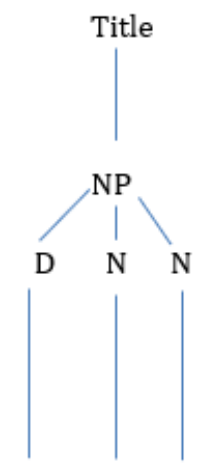

The women's courtyard

The graphic used in the title pages according to Davy (2013) is a picture of a courtyard where a woman is standing in the balcony according to the title of the novel. Author has not shown the regular boundaries. Arch type boundaries, discontinuous boundaries of the courtyard like the boundaries of citadels, signifies a woman presented at the corner of a typical arch and she is not present in the middle of the courtyard, which means the courtyard in possession of the women of the apostrophe of the title. Actually, contrasts the position of the women in the figure. He has used purple color for the courtyard. Purple conjures up images of richness and extravagance, as well as fantasy and the realm of dreams. It facilitates spiritual growth and awareness. Purple heightens people's sense of beauty and their responsiveness to more innovative thoughts physiologically. As the title of the novel shoes that the courtyard is devoted to the women, purple is typically used to represent a high grade or excellent goods. Purple is a colour associated with monarchy, mysticism, and nobility. Purple is better suited to items and websites aimed at women or children, as the author in the title page is a woman. The colour white is utilised on one side of the balcony to represent softness and cleanliness (Cerrato, 2012). No one before this author used purple color for the graphics of the title page. He used very different colors in the title page among all the other authors. 
Setting the title page according to the Bernstein (2003), the author used the graphical features according to the title of the novel. He has shown courtyard and the woman in the picture as he has mentioned both of them in the title. He has used different color in the graphics of his title page as compared to the other authors or the title pages analyzed till now. Graphics of the title page reveal that the author is discussing something about women's rights and power in his content.

\section{CONCLUSION}

The primary objective of the current study was to investigate the textual, graphical and situational features present in title pages of English novels by native and non-native authors with the help of Multimodal analysis propounded by Jeffries (2016), Davy (2013), and Bernstein (2003) respectively. The secondary aim of this research was to compare the richness of graphic features of title pages of English novel by native authors as well as non-native authors. Moreover, it also highlights the contextual features of the title pages, which mean the context of the title pages in which various graphic, textual and situational features are being used by the author according to the content of the novel.

The text of the title composed by native composers indicates the use of various modifiers to modify the meaning of the nouns or to make their titles more attractive, wonderful and salient. They used different propositions in their titles to connect different phrases, which complete the sense and make the title more beautiful. The native authors wrote their name at the end of the title page and equally highlighted them, which shows that they have given equal importance to the titles of the novels and the authors because mature readers pay attention to the authors of the novels too. Non-Native authors also comprise the titles of the novels of simple structure. Native authors have composed the titles in almost the same structure that supports the idea that they have followed some models or theories while composing the title but the non-native authors have shown the title in different structure.

The second research objective has been pursued by analyzing the graphics of the title pages of English novels by native and non-native authors with the 
help of Jeffries' (2016) model of Textual Conceptual Functions (TCFs). The title pages of English novel were taken from both native and non-native authors and then analyzed through this model. Colors play a vital role in the depiction of theme and situation of the content. While selecting a title page, a publisher must finalize those colors of the title page, which must reveal the situation as discussed in the content of the piece of literature composed by author. The title page gives the maximum information of the content. With a single bird eye view, the reader or the viewer can judge or analyze what kind of content is present in this entire document. Authors should be very careful; they should follow the great linguist while selecting colors and background situation. Then, they consult their publisher for the finalization of the title pages because title page plays a very important role in the popularity of the piece of literature if they want to increase the maximum readership.

Now as for as the third objective of this research investigation is concerned, there has been an attempt to answer with the help of the theory propounded by Bernstein (2003). The maximum information that has been extracted by the readers or the viewers of the title pages, which have been portrayed by the native authors because they have given much information in the setting of the title page as the study, shows that the native authors have followed the theory while composing the title pages of the English novels. The non-native authors have not given plenty of information in the setting of the title page. It seems that they do not follow the theory while finalizing the setting of the title page.

From the results of the analysis, it can be concluded that native authors put additional information in the setting of their title pages and use situational features in the title pages according to the content of the novel. They follow models based on theories of experts in the field of semiotics and graphics and stylistics while finalizing their title pages. On the other hand, non-native authors seem to not follow any theory or model while composing the setting of the title pages of their creative text because they do not use situation and context accurately and according to the content of the piece of literature. Selecting features from the language, colours for text and figures as well as the theme of background scenery and relating them to situational variables using different 
quantification techniques, with the method of selection according to the aforementioned models, is necessary to associate the information relevant to the content of the subject matter present in whole of the document. It helps empower readers' visual intelligence to speculate more information about the piece of fiction. Moreover, the publisher, as well as author, accurately selects the appropriate setting that actually confirms the situation present in the text that has been composed by the authors. Obviously, it enhances the readers' engagement in the literary genre as the communicative effect of text also depends upon the visuality of images, the orality of soundscapes.[rgt]

\section{REFERENCES}

Ahmad, N. et al. (2015). A Psycho-Linguistic Exploration of Color Semantics. Journal of Literature, Languages and Linguistics. 16 (01), 1-6

Barkas, M. (2016). Magical Rings in English Literature. From Anglo-Saxon Charms to Tolkien's Lord of the Rings. GRIN Verlag.

https://www.grin.com/document/323880.

Bernstein, B. (2003). Class, codes and control: Towards a Theory of Educational Transmission. Routledge, London.

Bouza, N. (2017). Paratext, Title-pages and Grammar Books. Studia Neophiologica, 89: 41-66

Cresswell, J. (2014). Research Methodology-Qualitative, Quantitative, and Mixed Method. SAGE Publication India PVT Ltd.

Crystal, D. (2003). The Cambridge Encyclopedia of the English Language. Cambridge: Cambridge University Press.

Davy, D. \&. Derek. 2013. Investigating English Style. London: Routledge London. https://www.routledge.com/Investigating-English-Style/Crystal

De Saussure, F. (2011). Course in general linguistics. Columbia University Press.

Dicks, B. (2019). Multimodal Analysis. SAGE Publication. 
Fomukong, S. E. A. (2016). Stylistics analysis in advertising discourse: A case of the dangote cement advertisement in Bamenda-Cameroon. Advances in Language and Literary Studies, 7(6), 105-112.

Fomukong, S. E. A. (2017). Stylistic Structuring: Syntactic Patterns of Advertising Slogans in Bamenda Urban Council of the North West Region of Cameroon. British Journal of English Linguistics, 5(4), 1-16.

Hafiza, M., \& Rosa, R. N. (2020). An Analysis of Word Formation Of English Slang Used In Straight Outta Compton Movie. English Language and Literature, $9(1)$.

Halliday, M.A.K.(1985) An Introduction to Functional Grammar, Routledge, London

Hameed, N. S. (2017). A Semiotic Analysis of Iconic Genocide Images. Journal of AlNisour University College, 2(2).

https://www.researchgate.net/publication/332289941_A_Semiotic_Analy sis_of_Iconic_Genocide_Images

Jeffries, L. (2016). Stylistics. Cambridge University Press, UK.

Kress, G. (2015). Applied linguistics and a social semiotic account of multimodality. John Benjamins Publishing Company.

Kress, G. \& Leeuwen, V. (2006). Reading Images. Routledge, London.

Meghamala. S. \& Tavaragi1, M. S. (2016). Colors and Its Significance. The International Journal of Indian Psychology, 17.

Onursoy, S. (2015). A semiotic analysis of an Activist Image in Social Media. Online Journal of Art and Design, 3(2), 1-13.

Paltridge, B., \& Phakiti, A. (2015). Research methods in applied linguistics: A practical resource. Bloomsbury Publishing.

Qing, Q. I. U. (2019). A Multimodal Analysis of the Interplay between Visual and Verbal Semiotics in Creating Messages in Chinese Picture Books. Studies in Literature and Language, 19(3), 44-50.

Sabahat, S. A., \& Anwar, B. (2017). Social Meaning Making of Preschoolers through Animated Videos: A Multimodal Social Semiotic Analysis. NUML Journal of Critical Inquiry, 15(2), 103-107

Savitri, M. T., \& Rosa, R. N. (2019). A study of Multimodal Analysis in Smartphone Advertisement. English Language and Literature, 8(3). 
Shariq, M. (2020) Tools and Techniques Used in the Language of Advertisements: The Linguistic Perspective. https://www.researchgate.net/publication/344710164_Tools_Technique s_used_in_the_Language_of_Advertisements_A_Linguistic_Analysis_of_India n_TV_Commercial_Ads.

Turkcan, B. (2013). Semiotic Approach to the Analysis of Children's Drawings. Educational Sciences: Theory and Practice. ERIC 13(1), 600-607: https://eric.ed.gov/?id=EJ1016743

Twyman, M. (1979). A schema for the study of graphic language (tutorial paper). In Processing of visible language (pp. 117-150). Springer, Boston, MA.

Vasiloaia, M. (2009). Linguistic Features of the Language of Advertising. Semantic Scholar: No.1, 294-98. 
This page has been intentionally left blank. 